\title{
Sistem Informasi Pengolahan Data Penyelenggaraan Skripsi Mahasiswa Menggunakan Metode Waterfall (Studi Kasus IAIN Batusangkar)
}

\author{
Khairunnisa $^{1^{*}}$, Defiariany ${ }^{2}$, Keukeu Rohandi ${ }^{2}$ \\ ${ }^{I}$ Manajemen Informatika IAIN Batusangkar \\ ${ }^{2}$ Sistem Informasi STMIK Indonesia Padang \\ Jalan Sudirman No. 137, Lima Kaum, Kabupaten Tanah Datar, Sumatera Barat \\ *Email: khairunnisa@iainbatusangkar.ac.id
}

\author{
Article History \\ Received: 20 Mei 2020 \\ Reviewed: 5 Juni 2020 \\ Published: 30 Juni 2020

\section{Key Words} \\ System; Information; \\ Data processing; Thesis \\ Implementation; \\ Waterfall method.
}

\begin{abstract}
To facilitate the processing of thesis management reports, reports assignments, minutes and attendance, an application is needed. Dealing with these needs, an analysis of the processing of student thesis data processing needs to be done so that results and requirements can be obtained for the application that is need. The analysis was carried out by analyzing the needs, users and facilities needed by the application. The result of this study was the data processing information system for organizing student thesis using the waterfall method. There are 5 stages that were carried out in order to obtain maximum results, namely Communication (Project Initiation \& Requirements Gathering), Planning (Estimating, Scheduling, Tracking), Modeling (Analysis \& Design), Construction (Code \& Test), and Deployment (Delivery, Support, Feedback). The finding showed that this application helps facilitate the processing of thesis implementation data and displays the information needed by Batusangkar State Islamic Institute users.
\end{abstract}

\section{PENDAHULUAN}

Setelah judul skripsi diterima dan disetujui, mahasiswa ujian seminar proposal apabila lulus lanjut ke skripsi. Jurusan melakukan penunjukan terhadap dosen untuk menjadi pembimbing skripsi. Mahasiswa dapat bimbingan apabila surat tugas dosen pembimbing telah dikeluarkan oleh jurusan melalui pengajuan program studi. Permasalahannya adalah pembuatan surat tugas, berita acara dan absensi mahasiswa masih menggunakan

Berdasarkan masalah yang teridentifikasi di atas, maka penulis tertarik mengembangkan aplikasi pengolahan data penyelenggaraan semi komputer atau dibuat di Microsoft Word sehingga kemungkinan terjadinya duplikasi data masih ada.

Setelah itu adalah ujian Munaqasah. Pencatatan yang dilakukan di bagian program studi adalah jadwal ujian, ketua penguji, sekretaris penguji dan pembimbing. Sebelum ujian munaqasah skripsi, mahasiswa terlebih dahulu harus lulus ujian komprehensif. Setelah selesai ujian munaqasah skripsi dan dinyatakan lulus dikeluarkan rekap ujian.

skripsi sebagai solusi untuk mengatasi masalah tersebut. Agar dapat menghemat waktu dan memudahkan dalam pengerjaannya. 
Penelitian dengan metode waterfall sudah banyak dilakukan oleh peneliti dengan bermacam-macam masalah, diantaranya penelitian mengenai rancang bangun sistem informasi praktek kerja lapangan berbasis web dengan metode waterfall (Safitri \& Supriyadi, 2015) yang menjelaskan tentang pengembangan sistem informasi praktek kerja lapangan menggunakan metode waterfall. Penelitian mengenai tugas akhir juga pernah diteliti yaitu sistem informasi penilaian tugas akhir (Ramadhan, 2019) yang membahas penulisan tugas akhir mahasiswa.

Perbedaan penelitian ini dari penelitian sebelumnya adalah dari segi objek yang diteliti. Yang sebelumnya tentang praktek kerja lapangan dan penilaian tugas akhir sedangkan penelitian ini tentang pengolahan data penyelenggaraan skripsi mahasiswa mulai dari pengajuan judul sampai rekap ujian munaqasah.

\section{METODE PENELITIAN}

Metode penelitian yang dipakai pada penelitian ini yaitu metode waterfall. Model waterfall adalah model klasik yang bersifat sistematis, berurutan dalam membangun software (Pressman, 2015). Tahap-tahap metode waterfall ini tergambar di Gambar 1.

\section{A. Communication (Project Initiation \& Requirements Gathering)}

Seluruh kebutuhan harus didapatkan pada tahap ini dengan cara komunikasi dengan pengguna demi memahami dan mencapai tujuan yang diinginkan. Hasil dari komunikasi tersebut dianalisis secara rinci untuk digunakan pada tahap selanjutnya.

B. Planning (Estimating, Scheduling, Tracking)

Tahap ini menerangkan bagaimana estimasi pekerjaan yang akan dilakukan, resiko apa yang akan terjadi, sumber daya yang dibutuhkan, output apa yang akan dihasilkan, perencanaan waktu kerja yang akan dilaksanakan dan tracking proses pengerjaan aplikasi.

C. Modeling (Analysis \& Design)

Pada Tahap perancangan dan pemodelan ini terfokus pada perancangan struktur data, arsitektur program, tampilan program dan algoritmanya.

D. Construction (Code \& Test)

Tahap ini adalah proses menerjemahkan desain menjadi kode-kode atau bahasa yang dapat dibaca oleh mesin. Setelah kode selasai, maka dilakukan pengujian untuk menemukan kesalahan yang mungkin terjadi untuk direvisi.

E. Deploymen (Delivery, Support, Feedback)

Tahap ini adalah mengimplementasikan program ke pengguna, pemeliharaannya secara berkala, revisi, evaluasi, dan pengembangan program berdasarkan saran pengguna agar sistem dapat berjalan dan berkembang berdasarkan fungsinya.

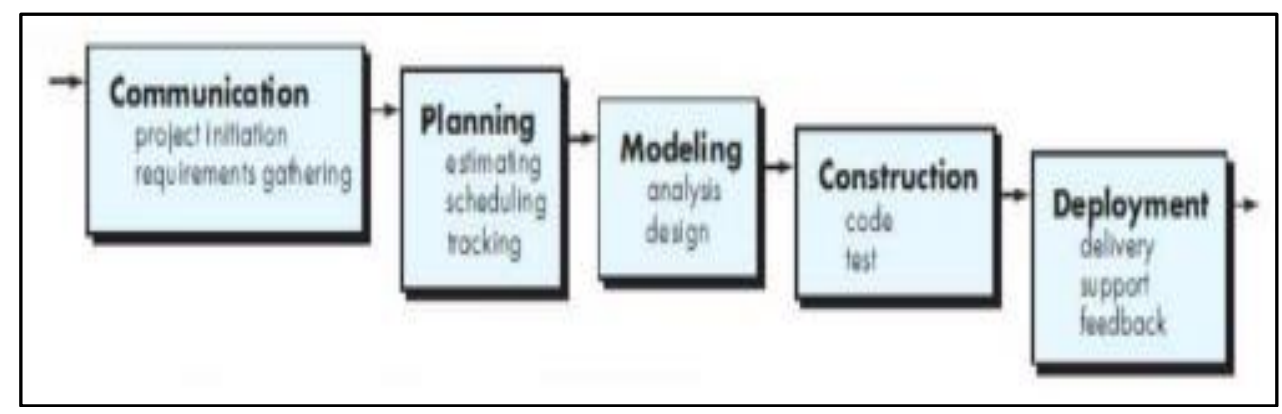

Gambar 1. Waterfall 


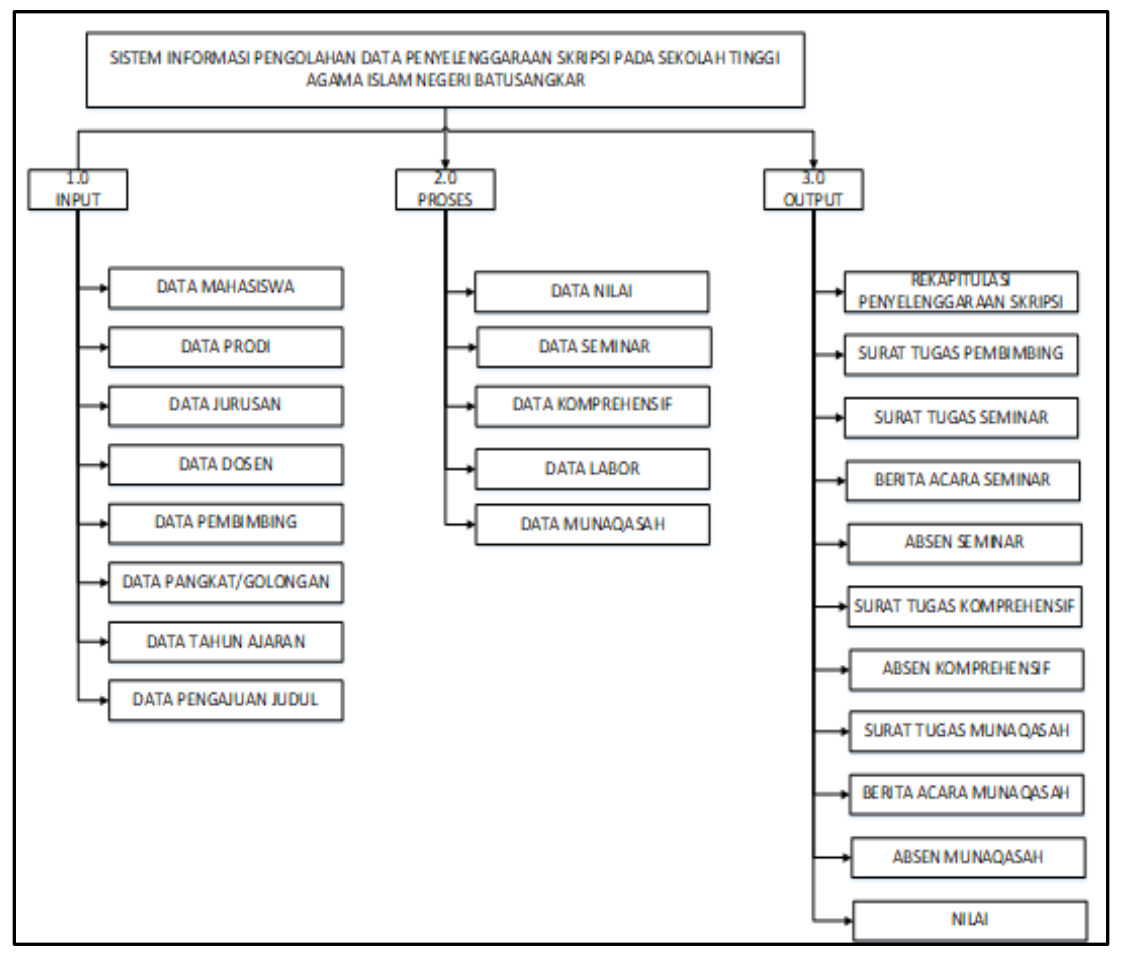

Gambar 2. Hierarchy Plus Input Process Output (HIPO)

\section{HASIL DAN PEMBAHASAN}

Hasil dari penelitian ini berdasarkan tahapan metode waterfall dapat disampaikan yaitu sebagai berikut:

A. Tahapan Communication (Project Initiation $\&$ Requirements Gathering)

Pada tahap ini penulis berkomunikasi dengan pengguna sehingga didapatkan bagaimana proses sistem yang sedang berjalan, kendala yang ada dan data-data yang dibutuhkan. Dengan adanya proses sistem, kendala dan data yang dibutuhkan penulis melakukan pengembangan sistem sesuai dengan keinginan pengguna dengan menggunakan metode waterfall.

B. Tahapan Planning (Estimating, Scheduling, Tracking)

Tahap ini dapat tergambar seperti pada Gambar 2.

Penjelasan dari Hierarchy Plus Input Process Output pada Gambar 2 yaitu:

1. Pada module utama 0.0 Sistem Informasi Pengolahan Data Penyelenggaraan Skripsi, memiliki 3 sub module yaitu sub module 1.0 Input, sub module 2.0 Proses dan sub module 3.0 Output.
2. Pada module 1.0 Input memiliki $11 \mathrm{sub}$ module yaitu sub module 1.1 Data Mahasiswa, sub module 1.2 Data Prodi, sub module 1.3 Data Jurusan, sub module 1.4 Data Dosen, sub module 1.5 Data Pembimbing, sub module 1.6 Data Pangkat/Golongan, sub module 1.7 Data Tahun Ajaran, sub module 1.8, Data Pengajuan Judul.

3. Pada module 2.0 Proses memiliki 1 proses yaitu sub module 2.1 Pengolahan Data Nilai, sub module 2.2 Data Seminar, sub module 2.3 Data Komprehensif, sub module 2.4 Data Labor, sub module 2.5 Data Munaqasah.

4. Pada module 3.0 Output memilik 3 sub module yaitu sub module 3.1 Rekapitulasi Penyelenggaraan Skripsi, sub module 3.2 Surat Tugas Pembimbing, sub module 3.3 Surat Tugas Seminar, sub module 3.4 Berita Acara Seminar, sub module 3.5 Absensi Seminar, sub module 3.6 Surat Tugas Komprehensif, sub module 3.7 Absensi Komprehensif, sub module 3.8 Surat Tugas Munaqasah, sub module 3.9 Berita Acara Munaqasah, sub module 3.10 Absensi Munaqasah, sub module 3.11 Nilai. 


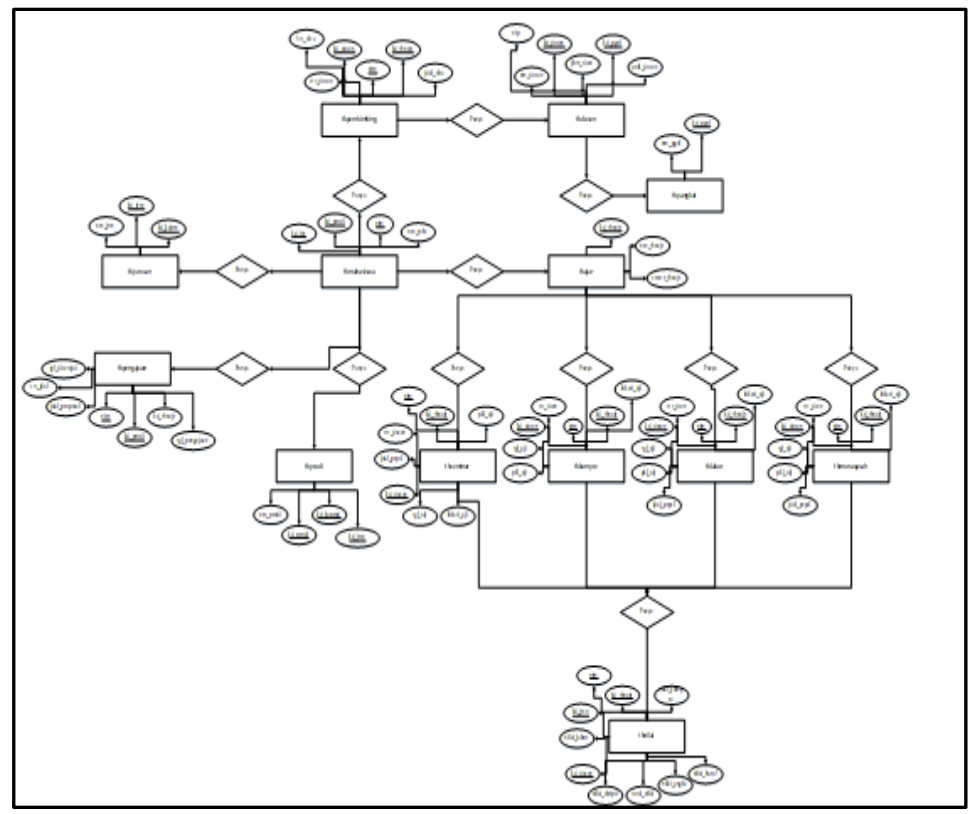

Gambar 3. Entity Relationship Diagram (ERD)

\section{Tahap Modeling (Analysis \& Design)}

Pada tahap ini terdapat tiga desain yaitu desain database menggunakan ERD, dan desain terinci yang terdiri dari struktur menu utama, desain output, desain input, desain proses, dan desain file. Desain ERD tergambar di Gambar 3.

Penjelasan dari Entity Relationship Diagram pada Gambar 3 yaitu:

1. ERD memiliki 13 entitas yaitu tbmahasiswa, tbprodi, tbjurusan, tbdosen, tbpembimbing, tbpangkat, tbajar, tbpengajuan, tbseminar, tbkompre, tblabor dan tbmunaqasah.

2. Pada entitas tbmahasiswa, banyak tbmahasiswa mempunyai satu tbprodi (M:1) dalam tbmahasiswa memiliki atribut nim, nm_mhs, kd_prodi dan kd_jrsn dengan nim sebagai primary key, kd_prodi dan kd_jrsn sebagai Foreign key.

3. Pada entitas tbprodi, tbprodi memiliki tbmahasiswa (M:M) dalam tbmahasiswa memiliki atribut kd_prod, nm_prod, $\mathrm{kd} \_k a p r o d, k d \_j r s n$ dengang $\mathrm{kd}$ _prod sebagai primary key.

4. Pada entitas tbjurusan, tbjurusan memiliki tbmahasiswa (M:M) dalam tbjurusan memiliki atribut kd_jrsn, nm_jrsn dan kd_kajrsn dengan kd_kajrsn sebagai primary key.

5. Pada entitas tbdosen, tbdosen memiliki tbmahasiswa (M:M) dalam tbdosen memiliki atribut kd_dsen, nm_dsen, nip, kd_pgol, jbtn_dsen dan unik_dsen dengan kd_dsen sebagai primary key.

6. Pada entitas tbpembimbing, tbpembimbing memiliki 1 tbdosen (M:1) dalam tbpembimbing memiliki atribut kd_thnajr, nim, kd_dsen, sts_dsen, jdul_skta dan sts_skta dengan kd_thnajr sebagai primary key.

7. Pada entitas tbpangkat, 1 tbpangkat memiliki 1 tbdosen (1:1) dalam tbpangkat memiliki atribut kd_pgol dan nm_pgol dengan kd_pgol sebagai primary key.

8. Pada entitas tbajar, 1 tbajar memiliki 1 tbseminar (1:M) dalam tbajar miliki atribut kd_thnajr, nm_thnajr dan smstr_thnajr dengan kd_thnajr sebagai primary key. Pada tbseminar miliki atribut kd_thnajr, nim, kd_dsen, sts_dsen, jdul_prpsl, tgl_uji, pkl_uji dan lokasi_uji dengan kd_thnajr sebagai primary key dan nim dan kd_dsen sebagai foreign key.

9. Pada entitas tbajar, 1 tbajar memiliki 1 tbkompre (1:M) dalam tbajar miliki atribut kd_thnajr, nm_thnajr dan smstr_thnajr dengan kd_thnajr sebagai primary key. Pada tbkompre miliki atribut kd_thnajr, nim, kd_dsen, sts_dsen, tgl_uji, pkl_uji dan lokasi_uji dengan kd_thnajr sebagai primary key dan nim dan kd_dsen sebagai foreign key. 
10.Pada entitas tbajar, 1 tbajar memiliki 1 tblabor (1:M) dalam tbajar miliki atribut kd_thnajr, nm_thnajr dan smstr_thnajr dengan kd_thnajr sebagai primary key. Pada tblabor miliki atribut kd_thnajr, nim, kd_dsen, sts_dsen,jdul_prpsl,tgl_uji,pkl_uji dan lokasi_uji dengan kd_thnajr sebagai primary key dan nim dan kd_dsen sebagai foreign key.

11.Pada entitas tbajar, 1 tbajar memiliki 1 tbmunaqasah (1:M) dalam tbajar miliki atribut kd_thnajr, nm_thnajr dan smstr_thnajr dengan kd_thnajr sebagai primary key. Pada tblabor miliki atribut kd_thnajr, nim, kd_dsen, sts_dsen, jdul_skta, tgl_uji, pkl_uji dan lokasi_uji dengan kd_thnajr sebagai primary key dan nim dan kd_dsen sebagai foreign key.

12.Pada entitas tbseminar, 1 tbseminar memiliki 1 tbnilai (1:1) dalam tbseminar miliki atribut kd_thnajr, nim, kd_dsen, sts_dsen, jdul_prpsl, tgl_uji, pkl_uji dan lokasi_uji dengan kd_thnajr sebagai primary key dan nim dan kd_dsen sebagai foreign key. Pada tbnilai miliki atribut kd_thnajr, nim, kd_dsen, $\mathrm{kd} \_$jrsn, nilai_kompre, nilai_labor, nilai_skripsi, total_nilai, nilai_angka dan nilai_huruf dengan kd_thnajr sebagai primary key dan nim, kd_dsen dan kd_jrsn sebagai foreign key.

13.Pada entitas tbkompre, 1 tbkompre memiliki 1 tbnilai (1:1) dalam tbseminar miliki atribut kd_thnajr, nim, kd_dsen, sts_dsen, tgl_uji, pkl_uji dan lokasi_uji dengan kd_thnajr sebagai primary key dan nim dan kd_dsen sebagai foreign key. Pada tbnilai miliki atribut kd_thnajr, nim, kd_dsen, kd_jrsn, nilai_kompre, nilai_labor, nilai_skripsi, total_nilai, nilai_angka dan nilai_huruf dengan kd_thnajr sebagai primary key dan nim, kd_dsen dan kd_jrsn sebagai foreign key.

14.Pada entitas tblabor, 1 tblabor memiliki 1 tbnilai (1:1) dalam tbseminar miliki atribut kd_thnajr, nim, kd_dsen, sts_dsen, jdul_prpsl, tgl_uji, pkl_uji dan lokasi_uji dengan kd_thnajr sebagai primary key dan nim dan $\mathrm{kd}$ _dsen sebagai foreign key. Pada tbnilai miliki atribut kd_thnajr, nim, kd_dsen, $\mathrm{kd}$ jrsn, nilai_kompre, nilai_labor, nilai_skripsi, total_nilai, nilai_angka dan nilai_huruf dengan kd_thnajr sebagai primary key dan nim, kd_dsen dan kd_jrsn sebagai foreign key.

15.Pada entitas tbmunaqasah, 1 tbmunaqasah memiliki 1 tbnilai (1:1) dalam tbseminar miliki atribut kd_thnajr, nim, kd_dsen, sts_dsen, jdul_prpsl, tgl_uji, pkl_uji dan lokasi_uji dengan kd_thnajr sebagai primary key dan nim dan kd_dsen sebagai foreign key. Pada tbnilai miliki atribut kd_thnajr, nim, kd_dsen, kd_jrsn, nilai_kompre, nilai_labor, nilai_skripsi, total_nilai, nilai_angka dan nilai_huruf dengan kd_thnajr sebagai primary key dan nim, kd_dsen dan kd_jrsn sebagai foreign key.

Struktur Menu Utama merupakan tampilan pertama saat pengguna masuk ke dalam sistem.

Desain output untuk menggambarkan hasil dari proses yang tersimpan pada suatu database. Ada 11 desain output yaitu laporan rakapitulasi penyelenggaraan skripsi, surat tugas pembimbing, surat tugas seminar, berita acara seminar, absensi seminar, surat tugas komprehensif, absensi komprehensif, surat tugas munaqasah, berita acara munaqasah, absensi munaqasah dan rekap nilai mahasiswa.

Desain Input untuk menggambarkan masukan yang dibutuhkan dalam proses pembuatan laporan. Ada 8 desain input yaitu entry data mahasiswa, entry data prodi, entry data jurusan, entry data dosen, entry data pembimbing, entry data pangkat/golongan, entry data tahun ajaran dan entry data pengajuan judul.

Desain proses terdiri dari 5 yaitu data nilai, data seminar proposal, data komprehensif, data labor, data munaqasah.

Desain file terdiri dari yaitu login, mahasiswa, prodi, jurusan, dosen, pembimbing, pangkat/golongan, tahun ajaran, pengajuan judul, seminar proposal, komprehensif, labor, munaqasah dan nilai.

Dengan adanya seluruh desain di atas, maka arah rancangan system akan semakin jelas. D. Tahap Construction (Code \& Test)

Setelah desain rancangan selesai semuanya dilakukan pembuatan program dengan menggunakan visual studio 2010 dan MySQL. Aplikasi ini dibuat dalam bentuk menumenu yang mudah dimengerti dan disetujui oleh pengguna. Aplikasi ini berbasis desktop agar pengguna mudah dalam menjalankan sistem informasi. 
Tabel 1. Hasil Pengujian Blackbox Form Login

\begin{tabular}{llll}
\hline Test Case & Expected Result & Result & Conclusion \\
\hline Hanya mengisi username & $\mathrm{F}$ & $\mathrm{T}$ & Success \\
Input username yang salah & $\mathrm{F}$ & $\mathrm{T}$ & Success \\
Input login yang benar & $\mathrm{F}$ & $\mathrm{T}$ & Success \\
\hline
\end{tabular}

Setelah aplikasi dibangun dilakukanlah pengujian untuk melihat keamanan database dan aplikasinya, pengujian pada setiap elemen dalam aplikasi pengolahan data penyelenggaraan skripsi saat dioperasikan apakah sesuai dengan yang diinginkan dan berjalan dengan baik. Pengujian dilakukan menggunakan metode blackbox. Penulis juga melakukan pengujian pada proses pertama saat aplikasi dijalankan dengan verifikasi login. Login ini menggunakan hak aksesnya bagi pengguna dengan adanya username.

Penjelasan dari hasil pengujian Blackbox Form Login pada Tabel 1 yaitu

1. Tes hanya mengisi username, hasil yang diharapkan sistem akan menolak dan menampilkan pesan "Password belum diisi", hasilnya sesuai harapan dan kesimpulannya berhasil.

2. Tes input username yang salah, hasil yang diharapkan sistem akan menolak dan menampilkan pesan "Username yang anda masukkan salah", hasilnya sesuai harapan dan kesimpulannya berhasil

3. Tes input login yang benar, hasil yang diharapkan sistem menerima akses login dan kemudian menampilkan halaman utama admin, hasilnya sesuai harapan dan kesimpulannya berhasil.

Apabila pengujian telah berhasil dan layak diserahkan kepada pengguna, maka dilakukan pengenalan aplikasi tersebut kepada pengguna dan cara menjalankan aplikasi mulai dari login sampai download laporan yang ada.

\section{E. Tahap Deploymen (Delivery, Support, Feedback)}

Sistem telah selesai dibangun dan diuji pada tahap sebelumnya. Tahap ini melakukan pemeliharaan data yang dilakukan dengan dibackup dalam hardware dan software yang sesuai dengan kebutuhan agar sistem dapat berjalan dengan yang diharapkan. Pemeliharaan pada sistem upgrade juga dilakukan jika ada perubahan dari komponen yang ada pada aplikasi tersebut.

\section{KESIMPULAN}

Dengan sistem informasi pengolahan data penyelenggaraan skripsi mahasiswa ini nantinya dapat memudahkan dan membantu pekerjaan pengguna dalam mengolah data yang selama ini kurang efektif dan efisien serta dalam penyajian laporannya dapat menyajikan secara keseluruhan maupun per mahasiswa serta memberikan laporan seluruh transaksi secara akurat.

\section{DAFTAR KEPUSTAKAAN}

Larasati, H., \& Masripah, S. (2017). Analisa Dan Perancangan Sistem Informasi Pembelian GRC dengan Metode Waterfall. Pilar Nusa Mandiri, 193-198.

Pressman. (2015). Retrieved from http://library.binus.ac.id/eColls/eThesisdoc /Bab2/2014-2-01054-MTIF\%20Bab 2001.pdf

Ramadhan, W. F. (2019). Sistem Informasi Penilaian Tugas Akhir. Official Scientific Journals Of UII.

Rifai, A., \& Yuniar, Y. P. (2019, Juni). Penerapan Metode Waterfall Dalam Perancangan Sistem Informasi Ujian Pada SMK Indonesia Global Berbasis Web. Khatulistiwa Informatika. doi:https://doi.org/10.31294/jki.v7i1.5736

Romadhoni, E. N., Widiyaningtyas, T., \& Pujianto, U. (2015). Implementasi Model Waterfall Pada Pengembangan Sistem Informasi Alumni SMKN 1 Jenagan Ponorogo. Seminar Nasional Sistem Informasi Indonesia (SESINDO) (pp. 445452). Semarang: Departemen Sistem Informasi ITS.

Safitri, S. T., \& Supriyadi, D. (2015). Rancang Bangun Sistem Informasi Praktek Kerja Lapangan Berbasis Web dengan Metode Waterfall. Informatics, Telecommunication, and Electronics. doi:https://doi.org/10.20895/infotel.v7i1.32 